CLINICAL STUDY

\title{
Mutational spectrum of congenital adrenal hyperplasia in Slovenian patients: a novel Ala15Thr mutation and Pro30Leu within a larger gene conversion associated with a severe form of the disease
}

\author{
V Dolžan, M Stopar-Obreza ${ }^{1}$, M Žerjav-Tanšek ${ }^{1}$, K Breskvar, C Kržišnik ${ }^{1}$ and T Battelino ${ }^{1}$ \\ Institute of Biochemistry, Faculty of Medicine, University of Ljubljana, Ljubljana, Slovenia and ${ }^{1}$ University Children's Hospital, \\ Department of Pediatric Endocrinology, Diabetes and Metabolic Diseases, Ljubljana, Slovenia \\ $V$ Dolžan and M Stopar-Obreza contributed equally to this work \\ (Correspondence should be addressed to T Battelino, University Children's Hospital, Vrazov trg 1, SI-100O Ljubljana, Slovenia; \\ Email: tadej.battelino@mf.uni-lj.si)
}

\begin{abstract}
Objective: To analyse the mutational spectrum, the associated haplotypes and the genotype-phenotype correlation, and to design a reliable and rational approach for CYP21 mutation detection in Slovenian congenital adrenal hyperplasia $(\mathrm{CAH})$ patients.

Design: Molecular analysis of the CYP21 gene was performed in 36 CAH patients and 79 family members.

Methods: Southern blotting, sequence-specific PCR amplification (PCR-SSP), sequence-specific oligonucleotide hybridisation (PCR-SSO) and sequencing were used to detect CYP21 gene deletions, conversions and point mutations.

Results: CYP21 gene deletion was the most frequent mutation (36.4\%). Large gene conversions detectable only by Southern blotting represented $12.1 \%$, and gene conversions involving the promoter region represented $7.6 \%$ of the mutated alleles. The most frequent point mutations were: intron 2 splice mutation 16.7\%, Ile172Asn mutation 7.6\%, Gln318Stop 7.5\% and Pro30Leu $12.2 \%$ of alleles. A correlation between the genotype and the clinical phenotype similar to those described for large populations was observed. The finding of Pro30Leu mutation linked to a gene conversion could explain the simple virilising (SV) phenotype in compound heterozygotes for the Pro30Leu and a severe mutation. In two siblings with a salt wasting form of CAH (SW-CAH), a novel mutation Ala15Thr was found on the allele characterised by Pro30Leu mutation and gene conversion involving the promoter region.

Conclusions: Our genotyping approach allowed reliable diagnosis of $\mathrm{CAH}$ in the Slovenian population. The high frequency of CYP21 gene aberrations on Pro30Leu positive alleles justified systematic searching for a gene conversion in the promoter region using the PCR-SSP reaction.
\end{abstract}

European Journal of Endocrinology 149 137-144

\section{Introduction}

Congenital adrenal hyperplasia $(\mathrm{CAH})$ is a group of autosomal recessive disorders caused by defective adrenal steroidogenesis. More than $90 \%$ of the cases are due to mutations in the cytochrome P450 21-hydroxylase gene (CYP21) coding for the steroid 21-hydroxylase (21-OH) (1). Inherited defects of this enzyme, required for conversion of 17-hydroxyprogesterone (17-OHP) to 11-deoxycortisol, lead to various degrees of impaired cortisol and aldosterone synthesis and to androgen excess $(1,2)$. If $21-\mathrm{OH}$ is absent or completely inactive the disease manifests as a salt wasting form (SW-CAH) deficients cortisol and aldosterone synthesis. The symptoms of SW-CAH manifest early after birth - in girls with ambiguous external genitalia, in boys often as a salt-losing crisis. In the simple virilising form of $\mathrm{CAH}$ (SV-CAH) aldosterone synthesis is sufficient. Different extents of virilisation of the external genitalia are present in girls, while in boys early precocious puberty is usually the first sign of disease. In non-classical $\mathrm{CAH}(\mathrm{NC}-\mathrm{CAH})$ the disease is mild and usually not detected until later in life $(2,3)$.

The extent of enzyme impairment and the clinical phenotype of the disease is determined by the severity of the genetic defect in the CYP21 gene (3). The active gene, CYP21, is $98 \%$ homologous to the pseudo gene, CYP21P, which is non-functional due to 
several mutations $(4,5)$. Both genes are located within the HLA class III region on chromosome $6 \mathrm{p} 21.3$ and form two C4/CYP21 units with adjacent complement $\mathrm{C} 4 \mathrm{~A}$ and $\mathrm{C} 4 \mathrm{~B}$ genes (6). High sequence identity and close proximity of the two genes facilitate gene recombination and gene conversion events in this region, resulting in gene deletions, duplications or large gene conversions (7). Random point mutations may occur but are rare in CYP21 (8). The most likely mutations defined by those pre-existing in the CYP21P pseudo gene can easily be assayed on selectively amplified CYP21 gene sequences by allele-specific amplification or by oligonucleotide hybridisation. However, the frequent recombination events in this region resulting in alleles with changed gene copy number or in alleles carrying multiple mutations complicate molecular genetic diagnosis. Additionally, many patients with $\mathrm{CAH}$ are compound heterozygotes, having inherited a different mutation in each CYP21 allele. The severity of disease is determined by the activity of the less severely affected of the two alleles; however more than one clinical phenotype can be associated with some of the mutations $(4,9-11)$.

A study on the incidence of 21-OH deficiency in Slovenian hyper androgenic women pointed out that the mutational spectrum of the CYP21 gene in the Slovenian population might differ from the surrounding populations (12). The observed frequency of carriers of CYP21 gene conversion/deletion was much higher, but the frequency of the Val281Leu mutation was much lower than in a comparable group of Italian hyper-androgenic women (13).

The aims of this study were to analyse systematically the mutational spectrum and the associated haplotypes, as well as the genotype-phenotype correlation, in $\mathrm{CAH}$ patients and their family members registered in Slovenia, and to design a reliable and rational approach for CYP21 mutation detection needed for the purpose of pre-, peri- and postnatal diagnosis and for genetic counselling in our population.

\section{Patients and methods}

Since 1971, 41 patients with $\mathrm{CAH}$ have been treated and followed up at the University Children's Hospital in Ljubljana. Among them, 33 families with 36 patients and 79 first degree relatives (16 siblings and 63 parents), in total 115 subjects, agreed to participate in the study. Written informed consent was obtained from all participants. The study design was approved by the Slovene Medical Ethics Committee (\#18-4-95).

The clinical diagnosis of different types of $21-\mathrm{OH}$ deficiency was made by paediatric endocrinologists based on the history, physical examination, electrolyte and hormonal data $(1,14)$. Patients with inadequate steroid hormone synthesis were defined as having the SW form when clinical and laboratory signs of renal salt wasting were present in the first months of life, the SV form if virilisation appeared before the age of 4 years and the late onset or non-classical (NC) form when the signs and symptoms of androgen excess became evident after the age of 4 years.

\section{Molecular analysis of CYP21 gene conversions/deletions}

DNA was isolated from peripheral blood leukocytes by the salting out method (15). CYP21 and C4 gene deletions, duplications and large gene conversions were analysed by Southern blot hybridisation of TaqI restricted genomic DNA with CYP21 and C4 genespecific cDNA probes as previously described (12). Because only TaqI digests were analysed, gene conversions involving the TaqI restriction site were not distinguishable from deletions of the CYP21 gene. Deletions/conversions of CYP21 were identified by the decreased intensity of the $3.7 \mathrm{~kb}$ TaqI fragment as compared with the $3.2 \mathrm{~kb}$ TaqI fragment (Fig. 1) (16).

To further characterise CYP21 gene rearrangements, two PCR reactions with sequence-specific primers (PCR-SSP) were used (Fig. 2). In the PCR-SSP-A reaction the presence of chimeric CYP21 gene originating from a 'classical' deletion of $30 \mathrm{~kb}$ including the $5^{\prime}$ part of CYP21 with a breakpoint between exons 7 and 8 , as well as large gene conversions involving

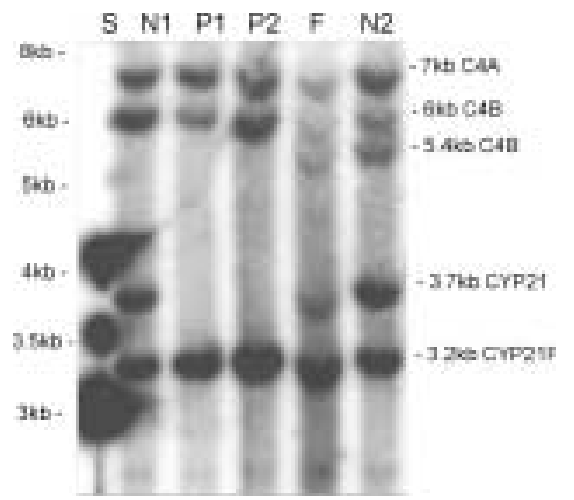

Figure 1 Southern blot hybridisation of Taql digested DNA hybridised with CYP21 and C4 probes. On the left side, the size of the fragments of radio-labelled standards (S) are shown in kilo bases (kb). On the right side, the fragment lengths in $\mathrm{kb}$ and their association with the corresponding gene are shown. N1, N2 - typical results of patients with two CYP21 genes; N1 has two $6 \mathrm{~kb}$ C4B fragments while N2 has one $6 \mathrm{~kb}$ and one $5.4 \mathrm{~kb}$ C4B fragment. $\mathrm{P} 1$ - a SW patient. The absence of $3.7 \mathrm{~kb}$ Taql band indicates a CYP21 gene conversion/deletion, decreased intensity of the $6 \mathrm{~kb}$ Taql fragment as compared to the $7 \mathrm{~kb}$ band indicates that this conversion/deletion also encompasses the C4B gene. P2 - a SW patient. The absence of the $3.7 \mathrm{~kb}$ Taql band indicates a CYP21 gene conversion/deletion which does not involve the $\mathrm{C} 4 \mathrm{~B}$ gene as indicated by the equal intensity of $6 \mathrm{~kb} \mathrm{C} 4 \mathrm{~B}$ and $7 \mathrm{~kb}$ C4A fragments. F -obligate carrier (father of $P 1$ ). The decreased intensities of the $3.7 \mathrm{~kb}$ CYP21 fragment as compared to the $3.2 \mathrm{~kb}$ CYP21P fragment indicate a conversion/deletion of one CYP21 allele. 


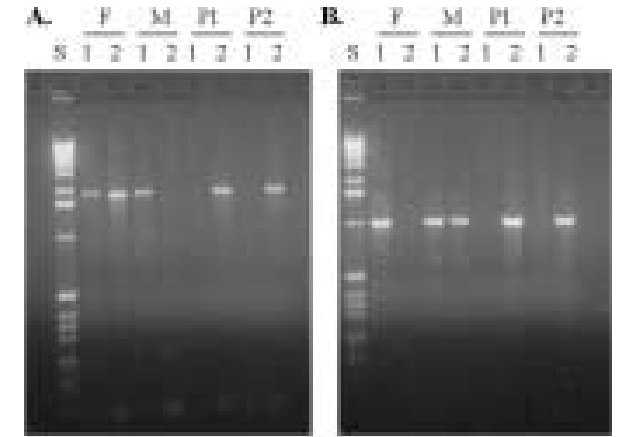

Figure 2 PCR-SSP reactions differentiating between CYP21 gene deletion and gene conversion in the promoter region. (A) PCRSSP-A. 1, amplification with CYP21-specific forward and CYP21specific reverse primers was used to amplify the normal sequence. 2, amplification with CYP21P-specific forward and CYP21-specific reverse primers. The presence of $1800 \mathrm{bp} \mathrm{PCR}$ product indicates the presence of a 'classical' deletion of $30 \mathrm{~kb}$ including the $5^{\prime}$ part of CYP21 with a break point between exons 7 and 8 , or a large gene conversion involving exon 6 as described in the methods section. S, $1 \mathrm{~kb}$ ladder; $\mathrm{F}$, father; $\mathrm{M}$, mother; $\mathrm{P} 1$, patient 13; P2, patient 14. (B) Similarly, a PCR-SSP-B reaction was set up to detect CYP21P/CYP21 recombinations in the region between -302 and exon 3 in order to establish whether the presence of the Taql restriction site in CYP21 is due to a gene deletion or a conversion event in this region, as described in the Patients and methods section. 1, amplification with CYP21specific forward and CYP21-specific reverse primers was used to amplify the normal sequence. 2, amplification with CYP21P-specific forward and CYP21-specific reverse primers was used to detect the allele with a recombination in the promoter region. S, 1 kb ladder; F, father; M, mother; P1, patient 13; P2, patient 14.

exon 6 were detected using the approach described by Chu et al. (17). Upon a presence of a recombination site a fragment of $1800 \mathrm{bp}$ spanning from exon 6 to $3^{\prime}$ untranslated region was amplified using a CYP21P-specific forward (ex6PF: 5'-GCCATAGAGAAGAGGGACCACAA) and CYP21-specific reverse (ex10R: 5'-TTAAGCCTCAATCCTCTGCAGCG) primer. An homologous, but CYP21-specific forward primer (ex6NF: 5'-GCCATAGAGAAGAGGGATCACAT) was used in a control reaction to amplify the normal sequence (Fig. 2A). PCR conditions were as described previously (17).

Similarly, a PCR-SSP-B reaction was set up. Two pairs of PCR primers were used to detect CYP21P/ CYP21 recombinations in the region between -302 and exon 3 in order to establish whether the presence of a TaqI restriction site in CYP21 is due to a gene deletion or a conversion event in this region. A CYP21P-specific (CAH-302P: 5'-GCGGACACCCTTGCCTGCACG) or CYP21-specific (CAH-302N: 5'-GCGGACACTATTGCCTGCACA) forward primer was used in combination with a CYP21-specific reverse primer (CAH-P2: 5'-AGCAGGGAGTAGTCTCCCAAG) to detect either the allele with a recombination in this region or the normal allele respectively (Fig. 2B). Additionally, allele-specific PCR was used to analyse for $8 \mathrm{bp}$ deletion in exon 3 (18).

\section{Point mutations analysis by sequence-specific oligonucleotide hybridisation (PCR-SSO)}

To screen for point mutations in CYP21 gene exons 1-3 and exons 3-10 were selectively amplified in all participants with two sets of primers using the $8 \mathrm{bp}$ deletion in exon 3 to distinguish between the functional CYP21 gene and the CYP21P pseudo-gene (3). Dot blot hybridisation analysis of the PCR product with $5^{\prime}$ biotinylated oligonucleotides was used to screen for the presence of normal or mutated sequences at the following sites of CYP21 gene: Pro30Leu (exon 1), A/C656G (in2) (-13 intron 2), Ile172Asn (exon 4), Ile-Val-Glu-Met236-239Asn-Glu-Glu-Lys (exon 6), Val281Leu (exon 7), insT307 (exon 7), Gln318Stop (exon 8) and Arg356Trp (exon 8) (12). Oligonucleotide sequences were essentially as previously described (3) only they were shorter at both ends by 2-3 nucleotides. An additional nine oligonucleotides were utilised to screen for the presence of GT1769CT splice site mutation (intone 7), Arg339His (exon 8), Pro453Ser (exon 10) and Arg/Pro484Ser (exon 10) (19).

\section{Sequencing analysis}

CYP21 gene and its proximal promoter region were first specifically amplified in two large fragments (12). Amplified fragments were purified on QIAquick PCR purification columns (Quiagen, Hilden, Germany) and sequenced with forward and reverse primers using Big Dye Terminator Cycle Sequencing Kit (Applied Biosystems, Warrington, Cheshire, UK) on an Abi Prism 310 Genetic Analyser. Sequencing primers were as previously described (12).

\section{Results}

In the present study we systematically genotyped 36 Slovenian $\mathrm{CAH}$ patients from 33 families, as well as 63 parents and 16 apparently healthy siblings. The clinical characteristics and genotyping results of the patients (probands) are shown in Table 1. Among 36 patients, 21 presented with SW-CAH (seven boys and 14 girls), nine had SV-CAH (four boys and five girls) and six had NC-CAH (two boys and four girls). The affected siblings with identical genotypes presented with a similar phenotype (patients 10-11, 13-14 and 26-27 in Table 1). Among 16 clinically normal siblings, nine were identified as carriers for CYP21 gene mutations (data not shown). Among parents, two mothers were found to be compound heterozygotes for mutations characteristic for NC-CAH (in2/Val281Leu and Pro30Leu/del respectively), while among four fathers two were homozygous for the in 2 mutation, one had the in $2 / \mathrm{Gln} 318$ Stop and one the Val281Leu/ del genotype. Interestingly, $\mathrm{CAH}$ was not recognised in any of these affected parents during their childhood, 
Table 1 Clinical characteristics and complete CYP21 genotypes of Slovenian CAH patients.

\begin{tabular}{|c|c|c|c|c|c|c|c|}
\hline \multirow[b]{2}{*}{ Patient } & \multirow[b]{2}{*}{ Status } & \multirow[b]{2}{*}{ Sex } & \multirow{2}{*}{$\begin{array}{c}\text { Age at } \\
\text { diagnosis }\end{array}$} & \multirow{2}{*}{$\begin{array}{l}\text { Clinical } \\
\text { phenotype }\end{array}$} & \multirow{2}{*}{$\begin{array}{l}\text { Virilisation } \\
\text { in females }\end{array}$} & \multicolumn{2}{|c|}{ CYP21 haplotypes } \\
\hline & & & & & & Paternal & Maternal \\
\hline 1 & $\mathrm{P}$ & $\mathrm{F}$ & $1 d$ & SW & SU & large conv & del \\
\hline 2 & $\mathrm{P}$ & $\mathrm{M}$ & $14 d$ & SW & & del & del \\
\hline 3 & $\mathrm{P}$ & $\mathrm{M}$ & $20 d$ & SW & & del & del \\
\hline 4 & $P$ & M & $20 d$ & SW & & del & del \\
\hline 5 & $P$ & $\mathrm{~F}$ & $16 \mathrm{~d}$ & sw & SU & del & del \\
\hline 6 & $\mathrm{P}$ & $\mathrm{F}$ & $10 \mathrm{~d}$ & sw & SU & del & del \\
\hline 7 & $\mathrm{P}$ & $\mathrm{F}$ & $3 d$ & SW & SU & del & del \\
\hline 8 & $\mathrm{P}$ & $\mathrm{F}$ & $7 d$ & sw & SU & del de novo & large conv \\
\hline 9 & $\mathrm{P}$ & $\mathrm{F}$ & $14 \mathrm{~d}$ & sW & SU & InsT307+Gln318Stop & del \\
\hline 10 & $\mathrm{P}$ & M & $10 \mathrm{~d}$ & sw & & InsT307+GIn318Stop & In2+Ex6+Val281Leu+GIn318Stop \\
\hline 11 & AS & M & $9 d$ & SW & & InsT307+Gln318Stop & In2+Ex6+Val281Leu+GIn318Stop \\
\hline 12 & $\mathrm{P}$ & $\mathrm{F}$ & $5 y$ & SV & $\mathrm{CM}$ & InsT307 & Gln318Stop \\
\hline 13 & $P$ & $\mathrm{~F}$ & $4 \mathrm{~m}$ & sw & $\mathrm{CM}$ & del & conv + Pro30Leu+Ala15Thr* \\
\hline 14 & AS & $\mathrm{F}$ & $21 d$ & sW & $\mathrm{CM}$ & del & conv+Pro30Leu+Ala15Thr* \\
\hline 15 & $\mathrm{P}$ & $\mathrm{F}$ & $14 \mathrm{~d}$ & SW & SU & Pro30Leu+ In2+ conv & large conv \\
\hline 16 & $\mathrm{P}$ & $\mathrm{F}$ & $12.3 y$ & NC & $\mathrm{CM}$ & large conv & conv+Pro30Leu \\
\hline 17 & $P$ & $\mathrm{M}$ & $3.5 y$ & SV & & conv+Pro30Leu & large conv \\
\hline 18 & $\mathrm{P}$ & $\mathrm{F}$ & $1.1 \mathrm{y}$ & SV & SU & conv + Pro30Leu & Gln318Stop \\
\hline 19 & $P$ & M & $12 d$ & SW & & del & $\ln 2$ \\
\hline 20 & $P$ & $\mathrm{~F}$ & $9 d$ & sw & SU & In2 & large conv \\
\hline 21 & $P$ & $\mathrm{~F}$ & $8 d$ & sw & SU & del & In2 \\
\hline 22 & $\mathrm{P}$ & $\mathrm{F}$ & $5 d$ & SW & SU & In2 & del \\
\hline 23 & $P$ & M & $24 d$ & SW & & $\ln 2$ & del \\
\hline 24 & $P$ & $\mathrm{~F}$ & $10 \mathrm{~d}$ & SW & SU & In2 & In2 \\
\hline 25 & $P$ & $\mathrm{~F}$ & $20 d$ & SW & SU & In2 & $\ln 2$ \\
\hline 26 & $P$ & $\mathrm{~F}$ & $0.8 y$ & SV & SU & del & Ile172Asn \\
\hline 27 & AS & M & $4 y$ & SV & & del & Ile172Asn \\
\hline 28 & $\mathrm{P}$ & $\mathrm{F}$ & $8 d$ & SV & SU & Ile172Asn & del \\
\hline 29 & $\mathrm{P}$ & $\mathrm{M}$ & $7.2 y$ & SV & & Ile172Asn & In2 \\
\hline 30 & $P$ & $\mathrm{~F}$ & $2 y$ & SV & $\mathrm{CM}$ & Ile172Asn & lle172Asn \\
\hline 31 & $P$ & $\mathrm{M}$ & $1 \mathrm{~m}$ & NC & & Pro453Ser & del \\
\hline 32 & $P$ & $\mathrm{M}$ & $6.8 y$ & NC/SV & & Pro30Leu & In2 \\
\hline 33 & $\mathrm{P}$ & $\mathrm{F}$ & $12 y$ & NC & & Pro30Leu & del \\
\hline 34 & $P$ & M & $7.2 \mathrm{y}$ & NC & & Pro30Leu & Val281Leu \\
\hline 35 & $P$ & $\mathrm{~F}$ & $6 y$ & NC & & Val281Leu & del \\
\hline 36 & $P$ & $\mathrm{~F}$ & $1.3 y$ & NC & SU & large conv & $\mathrm{N}$ \\
\hline
\end{tabular}

Status: P, proband; AS, affected sibling. Sex: F, female; M, male. Age at diagnosis: d, days; m, months; y, years. Clinical phenotype: SW, salt wasting; SV simple virilising; NC, non-classical. Virilisation in females: CM, clitoromegaly; SU, sinus urogenitalis. Haplotypes: del, CYP21 gene deletion; large conv, large CYP21 gene conversion; conv, CYP21 gene conversion involving the promoter region; In2, intron 2 splice mutation; N, normal; * novel mutation.

although some clinical signs (short stature and increased virilisation) were present in their adulthood.

Using sequence-specific oligonucleotide hybridisation (PCR-SSO), sequence-specific PCR amplification (PCRSSP), Southern blotting and sequencing we could identify the causative mutation on 65 out of 66 (98.5\%) unrelated disease alleles (Table 2). The one allele that could not be identified represents $1.5 \%$ of all unrelated alleles and belonged to an $\mathrm{NC}-\mathrm{CAH}$ patient having a CYP21 gene deletion on the second allele.

CYP21 gene deletions/conversions were found to be the most frequent mutation in Slovenian $\mathrm{CAH}$ patients. In order to characterise these alleles better PCR-SSP-A and PCR-SSP-B amplifications were performed in addition to Southern blotting. The parental origin of the converted/deleted alleles found in patients was determined by PCR-SSP analysis of the parents. Among 60 parents analysed by Southern blotting, 33 had decreased intensity of the $3.7 \mathrm{~kb} / \mathrm{TaqI}$ band when compared with the $3.2 \mathrm{~kb} /$ TaqI band. In 21 out of these 33 parents this could be attributed to classical CYP21 gene deletion or large gene conversion with a breakpoint between exon 6 and exon 10 based on the positive result of the PCR-SSP-A reaction. These alleles were designated as CYP21 gene deletion. In seven out of these 33 parents both the PCR-SSP-A and PCRSSP-B reactions amplified only normal alleles, suggesting that the absence of the $3.7 \mathrm{~kb} / \mathrm{TaqI}$ band might be due to a gene conversion with a breakpoint before exon 6 or to a gene conversion involving other regions. These alleles were designated as large gene conversion (large conv). In five out of these 33 parents the decreased intensity of the $3.7 \mathrm{~kb} / \mathrm{TaqI}$ band could be attributed to a gene conversion in the promoter region based on the positive result of the PCR-SSP-B reaction. Both PCR-SSO hybridisation analysis and the sequencing indicated that these conversions always encompassed codon 30, therefore they were designated as 
Table 2 Allele frequency of mutations detected in unrelated Slovenian $\mathrm{CAH}$ patients.

\begin{tabular}{lrr}
\hline Allele & Number & \% of alleles \\
\hline del & 24 & 36.4 \\
large conv & 8 & 12.1 \\
In2+ conv ex6-ex8 & 1 & 1.5 \\
conv+Pro30Leu & 3 & 4.6 \\
conv+Pro30Leu+Ala15Thr & 1 & 1.5 \\
conv+Pro30Leu+In2 & 1 & 1.5 \\
Pro30Leu & 3 & 4.6 \\
In2, splice & 11 & 16.7 \\
Ile172Asn & 5 & 7.6 \\
Val281Leu & 2 & 3.0 \\
Ins307T & 1 & 1.5 \\
GIn318Stop & 2 & 3.0 \\
Ins307T+GIn318Stop & 2 & 3.0 \\
Pro453Ser & 1 & 1.5 \\
N & 1 & 1.5 \\
Total & 66 & 100.0 \\
\hline
\end{tabular}

del, CYP21 gene deletion; large conv, large CYP21 gene conversion; conv, CYP21 gene conversion involving the promoter region; conv ex6-ex8, cluster of mutations in exon 6+Val281Leu+Gln318Stop; In2, intron 2 splice mutation. $\mathrm{N}$, normal.

conv+ Pro30Leu. We also observed that the PCR-SSPA reaction aimed to detect the classical CYP21 gene deletion amplified a specific product in all individuals positive for Val281Leu mutation, a finding which we explained by the presence of a duplicated CYP21P gene.

The frequencies of CYP21 gene mutations in Slovenian $\mathrm{CAH}$ patients were calculated based on systematic genotyping of 66 unrelated chromosomes. As shown in Table 2, CYP21 gene deletion was the most common cause of $\mathrm{CAH}$ and was found on $36.4 \%$ of unrelated alleles, large gene conversions detectable only by Southern blotting represented $12.1 \%$ and gene conversions involving the promoter region represented $7.6 \%$ of the mutated alleles The most frequent point mutations were intron 2 splice mutation found on $16.7 \%$ of the alleles and Ile172Asn mutation present on $7.6 \%$ of the alleles. Other point mutations detected were Gln318Stop on 7.5\% of alleles and Pro30Leu on $12.2 \%$ of alleles. Both were frequently found on chromosomes carrying additional point mutations or gene conversions involving the promoter region in the latter case. Gln318Stop was found as a single point mutation on three unrelated alleles and transferred en bloc with insT307 on two alleles. Alleles with multiple mutations were found in two siblings (patients 10 and 11 in Table 1). Val281Leu mutation was found on two unrelated alleles, while isolated insT307 and Pro453Ser mutations represented only single unrelated alleles.

As shown in Table 1, genotype-phenotype correlations observed in Slovenian $\mathrm{CAH}$ patients were similar to those reported from large populations (9). The finding of Pro30Leu mutation linked to a gene conversion or to an additional mutation could explain the SW or SV phenotype in patients who are compound heterozygotes for the Pro30Leu and a severe mutation. As shown in Table 3, nine compound heterozygotes for Pro30Leu were identified. Among them, Pro30Leu was transmitted as a single point mutation in only three patients, two of which presented with $\mathrm{NC}-\mathrm{CAH}$ and the third with NC/SV-CAH. In three patients Pro30Leu was transmitted en bloc with a gene conversion in the promoter region. Two of these patients presented with SV-CAH, while the third, a female with NC$\mathrm{CAH}$, presented with clitoromegaly. In three patients, all manifesting with SW-CAH, additional point mutations on the chromosome characterised by Pro30Leu mutation and gene conversion in the promoter region were identified - one patient had the intron 2 splice mutation while two siblings were hemizygous for a novel mutation Ala15Thr (Fig. 3) which has not been described to date in $\mathrm{CAH}$ patients. A schematic presentation of mutations detected in Slovenian CAH patients is shown in Fig. 4.

Table 3 Clinical characteristics and genotype-phenotype correlations in patients positive for Pro30Leu mutation.

\begin{tabular}{|c|c|c|c|c|c|c|c|c|}
\hline \multirow[b]{2}{*}{ Patient } & \multirow[b]{2}{*}{ Sex } & \multirow[b]{2}{*}{ Age } & \multirow{2}{*}{$\begin{array}{c}\text { Clinical } \\
\text { phenotype }\end{array}$} & \multirow{2}{*}{$\begin{array}{l}\text { Virilisation } \\
\text { of females }\end{array}$} & \multicolumn{2}{|c|}{ Patient's genotype } & \multirow{2}{*}{$\begin{array}{c}\text { PCR-SSP-B } \\
-302-\mathrm{ex} 3\end{array}$} & \multirow{2}{*}{$\begin{array}{c}\text { PCR-SSP-A } \\
\text { ex6-ex10 }\end{array}$} \\
\hline & & & & & Allele 1 & Allele 2 & & \\
\hline 13 & $\mathrm{~F}$ & $4 \mathrm{~m}$ & SW & $\mathrm{CM}$ & conv + Ala15Thr + Pro30Leu & del & $\mathrm{P}$ & $P$ \\
\hline 14 & $\mathrm{~F}$ & $21 \mathrm{~d}$ & SW & $\mathrm{CM}$ & conv+Ala15Thr+Pro30Leu & del & $P$ & $P$ \\
\hline 15 & $\mathrm{~F}$ & $14 \mathrm{~d}$ & SW & SU & conv+Pro30Leu+ In2 & large conv & $\mathrm{P}$ & $\mathrm{N}$ \\
\hline 17 & $M$ & $3.5 y$ & SV & & conv+Pro30Leu & large conv & $\mathrm{N} / \mathrm{P}$ & $\mathrm{N}$ \\
\hline 18 & $\mathrm{~F}$ & $1.1 \mathrm{y}$ & SV & SU & conv+Pro30Leu & Gln318Stop & $\mathrm{N} / \mathrm{P}$ & $\mathrm{N}$ \\
\hline 16 & $\mathrm{~F}$ & $12.3 y$ & NC & $\mathrm{CM}$ & conv+Pro30Leu & large conv & $\mathrm{N} / \mathrm{P}$ & $\mathrm{N}$ \\
\hline 32 & M & $6.8 y$ & NC/SV & & Pro30Leu & In2 & $\mathrm{N}$ & $\mathrm{N}$ \\
\hline 33 & $\mathrm{~F}$ & $12 y$ & NC & & Pro30Leu & del & $\mathrm{N}$ & $\mathrm{N} / \mathrm{P}$ \\
\hline 34 & M & $7.2 y$ & NC & & Pro30Leu & Val281Leu & $\mathrm{N}$ & $\mathrm{N} / \mathrm{P}$ \\
\hline
\end{tabular}

Sex: F, female, M, male. Age at diagnosis: d, days, m, months, y, years. Clinical phenotype: SW, salt wasting, SV, simple virilising, NC, non-classical. Virilisation of females: CM, clitoromegaly, SU, sinus urogenitalis. Patient's genotype: del, CYP21 gene deletion; large conv, large CYP21 gene conversion; conv, CYP21 gene conversion involving the promoter region. PCR-SSP-B sequence specific PCR for detection of CYP21 gene conversion in the promoter region (-302-ex3); PCR-SSP-A sequence specific PCR for detection of CYP21 gene deletion (ex6-ex10): N, CYP21-specific sequence amplified, P, CYP21P specific-sequence amplified. 


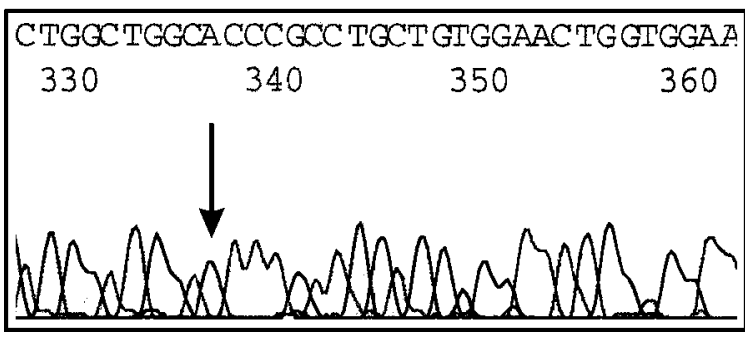

Figure 3 DNA sequence of part of exon 1 of the CYP21 gene in patient 13 (see Table 1). The arrow is pointing at the $G$ to $A$ transition at nucleotide 43 , which results in the hemizygous Ala to Thr mutation at codon 15. The paternal allele carried a CYP21 gene deletion and was not amplified by the PCR-SSP-B reaction. The (maternal) allele with a gene conversion in the promoter region was specifically amplified in the PCR-SSP-B reaction and sequenced with exon 1 forward sequencing primer (12). Further downstream, at nucleotide 89 , the $\mathrm{G}$ to $\mathrm{A}$ transition is present on the same allele, leading to the Pro to Leu mutation at codon 30 (not shown).

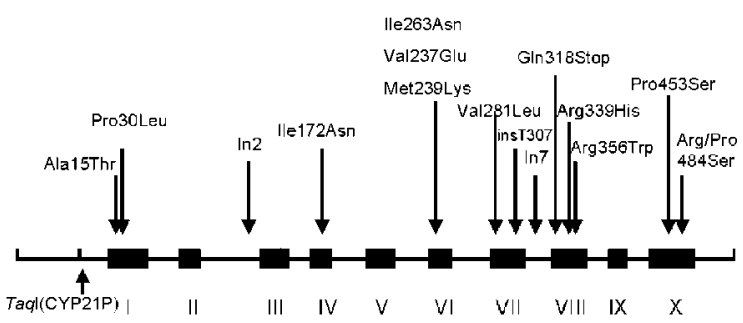

Figure 4 Schematic presentation of mutations detected in the Slovenian population of $\mathrm{CAH}$ patients, including the putative novel Ala15Thr point mutation.

\section{Discussion}

Systematic analysis of the mutational spectrum and the associated haplotypes, as well as the genotype-phenotype correlation, was performed in 36 Slovenian $\mathrm{CAH}$ patients and 79 family members. These patients are representative for 21-OH deficiency alleles in the Slovenian population with 41 patients registered since 1971 at the University Children's Hospital in Ljubljana where the $\mathrm{CAH}$ diagnosis and management is centralised.

In total, 115 individuals were analysed for the presence of 12 point mutations, the deletion of $8 \mathrm{bp}$ in exon 3 and for large rearrangements in the CYP21 gene. Southern blotting and the family segregation analysis allowed us to distinguish homozygosity from hemizygosity for mutations.

The first interesting finding was the very high frequency of CYP21 gene deletions and large gene conversions, representing $36.4 \%$ and $12.1 \%$ of unrelated disease alleles respectively. Gene conversions involving the promoter region were found on $7.6 \%$ of unrelated disease alleles. The only population reported so far with a similar frequency of CYP21 gene deletions/ conversions is British (45\%) (20), while in all the surrounding populations these frequencies are lower:
$38.3 \%$ in Italian (21), 31.0\% in Austrian (22) and 27.4 in German CAH patients (11). Due to the high frequency of CYP21 gene deletions/conversions we employed PCR-SSP amplification that enabled us to characterise these alleles better and which can be used for rapid screening and prenatal diagnosis as well as in cases where not enough genetic material is available for Southern blotting. The latter technique can distinguish between CY21 gene deletion and large conversion when at least two digestion reactions are used for restriction fragment length polymorphism (16) but a lot of genetic material is required and the method is labour intensive and time consuming. Using two PCR-SSP reactions we could assign the missing $3.7 \mathrm{~kb} / \mathrm{TaqI}$ band to a classical CYP2 1 gene deletion or to a gene conversion in the promoter region in $65.6 \%(21 / 32)$ and $15.6 \%(5 / 32)$ of parental alleles respectively. However $21.9 \%$ (7/32) of parental alleles with one missing $3.7 \mathrm{~kb} /$ TaqI band could not be assigned and they most probably represent a large gene conversion with a breakpoint before exon 6 . Employing only PCR-SSP analysis these gene conversions would be missed. Regarding the fact that the breakpoint area may vary and that conversion from CYP21 back to CYP21P may occur, a single PCR method may not be sufficient to substitute for Southern blotting, although many attempts have been made lately to speed up and simplify the analysis $(23-25)$.

The second important feature of 21-hydroxylase deficiency in the Slovenian population was the great diversity of clinical phenotypes in compound heterozygotes for Pro30Leu and a severe mutation. Already the first report on Pro30Leu emphasises that affected females frequently present with clitoromegaly (26). Many authors later reported observations of more severe clinical phenotype than predicted by genotyping in carriers of Pro30Leu mutation $(10,11,22)$. In the Slovenian population only one-third of $\mathrm{CAH}$ alleles positive for Pro30Leu mutation actually represent a single base substitution and result in NC-CAH. In the second third of Pro30Leu-positive alleles this mutation is a part of a gene conversion encompassing the promoter region and exon 1 . The existence of such alleles has previously been described in patients with the classical form of the disease $(22,24)$. However, on one-third of Pro30Leu-positive alleles we detected an additional point mutation besides gene conversion. This was the intron 2 mutation in one SW patient while in two siblings presenting with SW-CAH a substitution, Ala15Thr, was detected. This mutation has not been described to date in $\mathrm{CAH}$ patients and results in the change of a non-polar amino acid residue for a polar one and represents a putative novel mutation which leads to a similar clinical phenotype as the additional intron 2 mutation. A functional assay is needed to evaluate the relative contribution of Ala15Thr to the SW phenotype observed in these siblings. The high frequency of other CYP21 gene aberrations on 
Pro30Leu-positive alleles emphasised the importance of systematic searching for a gene conversion in the promoter region using the PCR-SSP reaction in patients positive for Pro30Leu, especially when a prenatal diagnosis and treatment are planned.

Another interesting finding was the low frequency of $\mathrm{NC}-\mathrm{CAH}$ and related mutations in the Slovenian population in comparison with surrounding populations in which a high incidence of $\mathrm{NC}-\mathrm{CAH}$ has been reported: for example $1 / 330$ in the Italian and 1/63 in the Croatian population (27). Only six out of 36 patients (two males, four females) presented with $\mathrm{NC}-\mathrm{CAH}$ (16.7\%), which implied a very low prevalence of $\mathrm{NC}-\mathrm{CAH}$ in the population. One possible explanation is that the majority of NC-CAH patients may not be detected until later in life, or may remain asymptomatic, especially males. Among the unrelated disease alleles non-classical mutations Val281Leu, the isolated Pro30Leu and Pro453Ser represented 3.0\%, 4.6\% and $1.5 \%$ respectively. These findings are in agreement with the finding of much lower frequency of Val281Leu mutation in Slovenian hyper-androgenic women than in a comparable group of Italian patients (13). In the Slovenian population, in contrast to the Croatian $\mathrm{NC}-\mathrm{CAH}$ patients and similar to the Italian patients, the association between Val281Leu mutation and HLA-B14, a marker characteristic for NC-CAH, was confirmed $(12,28,29)$.

The good correlation between the genotype and the clinical phenotype observed in our study can be attributed to systematic genotyping and the family segregation studies. The unbalanced sex ratio observed in SW-CAH patients (six males, 13 females) emphasises the need for biochemical/hormonal screening for $\mathrm{CAH}$ in Slovenian newborns (30). Genotyping for mutations in CYP21 gene has been proven to be a valuable diagnostic tool in cases when slightly elevated 17-OHP levels were detected during the neonatal screening (31).

In conclusion, the results of this study have brought new insights into the molecular pathology of the CYP21 gene in the Slovenian population, and the finding of a novel Ala15Thr mutation within a gene conversion involving the promoter region and Pro30Leu associated with a severe form of the disease has been described. Our genotyping approach allowed accurate and sensitive identification of CYP21 gene mutations in $\mathrm{CAH}$ patients and their families and represents a cornerstone for a reliable pre-, peri- and postnatal diagnosis and for adequate genetic counselling in our population.

\section{Acknowledgements}

This study was supported by grants from the Slovenian Ministry for Education, Science and Sport (\# J3-7880, J3-3096, L3-2003, J3-1196) and CEEPUS (SI-013).
Special thanks are due to Ms Jurka Ferran for her expert technical assistance.

\section{References}

1 White PC, New MI \& Dupont B. Congenital adrenal hyperplasia. New England Journal of Medicine 1987316 1519-1524.

2 White PC \& New MI. Genetic basis of endocrine disease 2: congenital adrenal hyperplasia due to 21-hydroxylase deficiency. Journal of Clinical Endocrinology and Metabolism 1992 74 6-11.

3 Speiser PW, Dupont J, Zhu D, Serrat J, Buegeleisen M, Tusie-Luna MT et al. Disease expression and molecular genotype in congenital adrenal hyperplasia due to 21-hydroxylase deficiency. Journal of Clinical Investigations 199290 584-595.

4 White PC, New MI \& Dupont B. Structure of human steroid 21-hydroxylase genes. PNAS 198683 5111-5115.

5 Higashi Y, Yoshioka H, Yamane M, Gotoh O \& Fujii-Kuriyama Y. Complete nucleotide sequence of two steroid 21-hydroxylase genes tandemly arranged in human chromosome: a pseudogene and a genuine gene. PNAS $1986 \mathbf{8 3} 2841-2845$.

6 Dupont B, Smithwick EM, Oberfield SE \& Lee TD. Close genetic linkage between HLA and congenital adrenal hyperplasia (21-hydroxylase deficiency). Lancet 19772 1309-1312.

7 Urabe K, Kimura A, Harada F, Iwanaga T \& Sasazuki T. Gene conversion in steroid 21-hydroxylase genes. American Journal of Human Genetics 199046 1178-1186.

8 Helmberg A, Tusie-Luna MT, Tabarelli M, Kofler R \& White PC. R339H and P453: CYP21 mutations associated with nonclassic steroid 21-hydroxylase deficiency that are not apparent gene conversions. Molecular Endocrinology 19926 1318-1322.

9 Wedell A, Thilen A, Ritzen EM, Stengler B \& Luthman H. Mutational spectrum of the steroid 21-hydroxylase gene in Sweden: implications for genetic diagnosis and association with disease manifestation. Journal of Clinical Endocrinology and Metabolism 199478 1145-1152.

10 Wilson RC, Mercado AB, Cheng KC \& New MI. Steroid 21hydroxylase deficiency: genotype may not predict phenotype. Journal of Clinical Endocrinology and Metabolism $1995 \mathbf{8 0}$ 2322-2329.

11 Krone N, Braun A, Roscher AA, Knorr D \& Schwarz P. Predicting phenotype in steroid 21-hydroxylase deficiency? Comprehensive genotyping in 155 unrelated, well defined patients from Southern Germany. Journal of Clinical Endocrinology and Metabolism 2000 85 1059-1065.

12 Dolžan V, Preželj J, Vidan-Jeras B \& Breskvar K. Adrenal 21hydroxylase gene mutations in Slovenian hyperandrogenic women: evaluation of corticotrophin stimulation and HLA polymorphisms in screening for carrier status. European Journal of Endocrinology $1999 \mathbf{1 4 1} 132-139$.

13 Cuccia M, Blanche H, Dolžan V, Dondi E, Keller E, Mantovani V et al. Mutations of CYP21B gene (MHC class III) in pathologies other than congenital adrenal hyperplasia (CAH). In Genetic Diversity of HLA: Functional and Medical Implications. Proceedings of the 12th International Histocompatibility Workshop and Conference, vol. 1, pp 442-444. Ed. D Charron. Paris: EDK, 1997.

14 New MI, Lorenzen F, Lerner AJ, Kohn B, Oberfield SE, Pollack MS et al. Genotyping steroid 21-hydroxylase deficiency: hormonal reference data. Journal of Clinical Endocrinology and Metabolism $198357320-326$.

15 Miller SA, Dykes DD \& Polesky HF. A simple salting out procedure for extracting DNA from human nucleated cells. Nucleic Acid Research $1988 \mathbf{1 6} 1215$.

16 White PC, Vitek A, Dupont B \& New MI. Characterisation of frequent deletions causing steroid 21-hydroxylase deficiency. PNAS $1988 \mathbf{8 5} 4436-4440$.

17 Chu X, Braun-Heimer L, Rittner C \& Schneider PM. Identification of the recombination site within the steroid 21-hydroxylase gene (CYP21) of the HLA-B47, DR7 haplotype. Experimental and Clinical Immunogenetics 19929 80-85. 
18 Wilson RC, Wei J-Q, Cheng KC, Mercado AB \& New MI. Rapid deoxyribonucleic acid analysis by allele-specific PCR for detection of mutations in the steroid 21-hydroxylase gene. Journal of Clinical Endocrinology and Metabolism 199580 1635-1640.

19 Witchel SF, Lee PA, Suda-Hartman M \& Hoffman EP. Hyperandrogenism and manifesting heterozygotes for 21-hydroxylase deficiency. Biochemical and Molecular Medicine 199762 $151-158$.

20 Lako M, Ramsden S, Campbell RD \& Strachan T. Mutation screening in British 21-hydroxylase deficiency families and development of novel microsatellite based approaches to prenatal diagnosis. Journal of Medical Genetics 199936 119-124.

21 Balsamo A, Cacciari E, Baldazzi L, Tartaglia L, Cassio A, Mantovani $\mathrm{V}$ et al. Cyp21 analysis and phenotype/genotype relationship in the screened population of the Italian emigliromagna region. Clinical Endocrinology 200053 117-125.

22 Baumgartner-Parzer SM, Schulze E, Waldhausl W, Pauschenwein S, Rondot S, Nowotny P et al. Mutational spectrum of the steroid 21-hydroxylase gene in Austria: identification of a novel missense mutation. Journal of Clinical Endocrinology and Metabolism $2001864771-4775$.

23 Lee HH, Chang JG, Tsai CH, Tsai FJ, Chao HT \& Chung BC. Analysis of the chimeric CYP21P/CYP21 gene in steroid 21-hydroxylase deficiency. Clinical Chemistry 200046 606-611.

24 L'Allemand D, Tardy V, Gruters A, Schnabel D, Krude H \& Morel Y. How a patient homozygous for a 30-kb deletion of the C4-CYP21 genomic region can have a nonclassic form of 21-hydroxylase deficiency. Journal of Clinical Endocrinology and Metabolism 2000 $854562-4567$.

25 Oloney RC, Mougey EB, Wang J, Shulman DI \& Sylvester JE. Using real-time, quantitative PCR for rapid genotyping of the steroid 21-hydroxylase gene in a North Florida population. Journal of Clinical Endocrinology and Metabolism 200287 735-741.

26 Tusie-Luna MT, Speiser PW, Dumic M, New MI \& White PC. A mutation (Pro-30 to Leu) in CYP21 represents a potential nonclassic steroid 21-hydroxylase deficiency allele. Molecular Endocrinology 19915 685-692.

27 Speiser PW, Dupont B, Rubinstein P, Piazza A \& New MI. High frequency of nonclassical steroid 21-hydroxylase deficiency. American Journal of Human Genetics 198537 650-667.

28 Dumić M, Brkljačić L, Speiser PW, Wood E, Crawford C, Plavšić V et al. An update of frequency of non-classic deficiency of adrenal 21-hydroxylase in the Yugoslav population. Acta Endocrinologica $1990122703-710$.

29 Speiser PW, New MI \& White PC. Molecular genetics of nonclassical steriod 21-hydroxylase deficiency associated with HLA-B14 DR1. New England Journal of Medicine 1988319 $19-23$.

30 Kovacs J, Votava F, Heinze G, Solyom J, Lebel J, Priblincova Z et al. Lessons from 30 years of clinical diagnosis and treatment of congenital adrenal hyperplasia in five middle European countries. Journal of Clinical Endocrinology and Metabolism $2001 \mathbf{8 6}$ 2958-2964.

31 Nordenstrom A, Thilen A, Hagenfeldt L, Larsson A \& Wedell A. Genotyping is a valuable diagnostic complement to neonatal screening for congenital adrenal hyperplasia due to steroid 21-hydroxylase deficiency. Journal of Clinical Endocrinology and Metabolism 199984 1505-1509.

Received 13 November 2002

Accepted 2 May 2003 